\title{
Research and Development of a New Environmental-friendly Temperature-fixing Circuit Fuse with the Fire Extinguishing Function
}

\author{
Liu Sijia ${ }^{1, *}$ \\ ${ }^{1}$ College of Automation, Wuhan University of Technology, Wuhan, Hubei, China
}

\begin{abstract}
This paper made statistics on the proportion of electrical fires in total fire disasters in China, analyzed the causes of electrical fires as well as the current protective measures and their advantages and disadvantages, and introduced the composition, working principle, verification results of main technical parametersand application prospects of the new environmental-friendly temperature-fixing circuit fuse with the fire extinguishing function.
\end{abstract}

\section{Introduction}

According to the statistics, 802,000 electrical fires in total occurred in China from 2012 to 2020, and their number each year accounted for about $30 \%$ of the total national fire disasters, bring about serious casualties and economic and property losses. Through the analysis of electrical fire accidents in recent years, it is found that several reasons, such as short-circuits of wires, overloading of electricity and poor contact, contribute to these accidents. Their proportions are shown that: wire short-circuit about $48 \%$, poor contact about $15 \%$, electrical equipment aging about $12 \%$, poor quality of electrical equipment about $11 \%$, illegal operation about $8 \%$ and overloading of electricity about $6 \%{ }^{[1]}$. Overloading, overheating, short circuit and the like of electronic components or cables would incur electric spark or local overheating, resulting in excessive temperature and further firing. At the same time, since general firing locations of the components or cables are inside the electrical appliances or lines, it is difficult to detect, locate and inspect, and therefore an initial fire is easily to form and then spread quickly, leading to a big fire $^{[2]}$.

Compared with the developed countries, in the field of electrical fire related research in China started relatively late, since the late $1980 \mathrm{~s}$, made some standard for electrical fire, such as specifications for design of low voltage power distribution, the civil building electrical design specification, the leakage protector installed to run, the electrical fire monitoring equipment, etc. In the 21st century, Domestic electrical fire monitoring product emerge in endlessly. Most domestic manufacturer produce residual current detector and so on surveillance cameras, and production monitoring host, they adopt the unified communication interface, can form a complete set of electric fire monitoring system. In the construction of the system of electric fire monitor system and product realization technology, foreign related organizations in developed countries started early, Electrical fire protection code system has been formed. Although it started late in China, it adopts the same mature technology, and in recent years, with the introduction of relevant domestic standards and regulations, the electrical fire monitoring market is gradually improved and planned, and there is also an obvious growth trend ${ }^{[3]}$.

\section{Current extinguishing means for electrical fires}

Currently, special small fire-extinguishing devices, such as aerosol fire-extinguishing devices ${ }^{[4]}$ and fire-detecting tube fire-extinguishing devices ${ }^{[5]}$, are generally equipped in electrical appliances, aiming to cope with electrical fires. The working principle is that a fire detection device is triggered after an electrical fire occurs, and then the fireextinguishing device is started for fire extinguishing, thus effectively controlling casualties and economic and property losses. These types of devices, however, have four major shortcomings: first, when the fire extinguishing device is started, it shows that a big fire has occurred inside an electrical appliance and irreversible losses are caused, and the response time of fire detection is longer; second, it is impossible to automatically cut off the power supply, which leads to that the fire-occurring electrical appliance is energized all the time, and electric sparks or local overheating may occur, resulting in potential recurrence of the fire; third, the fire would inevitably lead to failures of circuits or electronic components inside the electrical appliance, and if the electrical appliance is still in an energized state, such failures are likely to lead to secondary damage; and fourth, the price of these devices is high, costing 1,000 yuan and above.

*lisite0803@126.cm 


\section{Research and development of the new environmental-friendly temperature- fixing circuit fuse with the fire extinguishing function}

\subsection{Research and development goals}

In view of the causes of electrical fire, we developed a new environmental-friendly temperature-fixing circuit fuse with the fire extinguishing function, which can solve the shortcomings of the existing fire extinguishing technology. Our research and development goals are as follows: first, it shall be installed on transmission lineusing as a circuit conductive part; second, it can cut off the power supply once the circuit is short-circuited or overloaded; third, it can sense the temperature near the installing position and act when reachinga preset temperature; and fourth, it necessarily has the fire extinguishing function, and the fire extinguishing agent should be environmental-friendly without damageto the circuit board.

\subsection{Research and development process}

According to the determined R\&D scheme, our new environmental-friendly temperature-fixing circuit fuse (hereinafter referred to as "the fuse") is composed of a temperature-sensitive blasting tube, a fire extinguishing agent, a fire extinguishing agent container, an air charging port, a sealing gasket, a top wire, a lead-antimony alloy, a wiring terminal, a shell package and the like. See Fig.1.

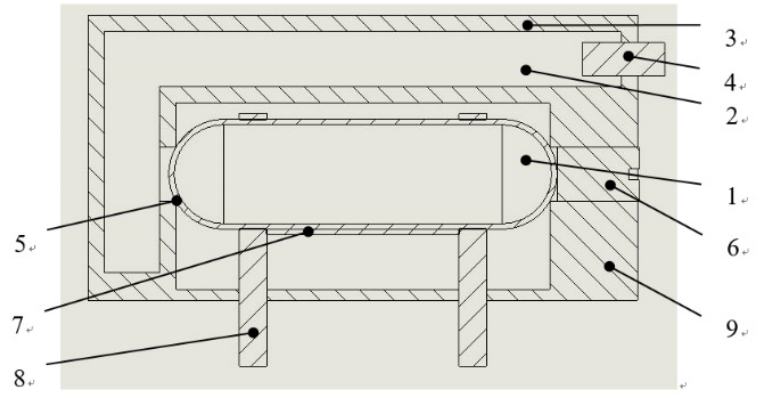

1-temperature-sensitive blasting tube, 2 - fire extinguishing agent,

3 - fire extinguishing agent container, 4 - air charging port; 5- sealing gasket,

6 - top wire, 7 -lead-antimony alloy, 8 - wiring terminal,

9- shell package containing colored liquid

Fig. 1. The new environmental-friendly temperature-fixing circuit fuse with the fire extinguishing function

The core component of the fuse is the temperaturesensitive blasting tube, which can achieve ourthree research and development goals. It is a temperaturesensitive glass ball ${ }^{[6]}$. The lead-antimony alloy includes a lead-antimony alloy wire or a lead-antimony alloy coating attached to the temperature-sensitive glass ball and used for circuit conduction. We limit the passing current by limiting the diameter of the lead-antimony alloy wire or the thickness/width of the lead-antimony alloy coating, thereby playing the role of a fuse wire for daily use. The temperature-sensitive glass ball is made of borosilicate heat-resistant glass, and the liquid filling the glass ball is a solution of ether, alcohol and the like, and a small bubble is reserved inside the ball. As the temperature rises, the liquid expands, the bubble is compressed and gradually reduced until it disappears completely, and at the moment the liquid completely occupies the glass ball. The temperature continues to rise, the glass ball explodes due to the expansion of the internal liquid, and the leadantimony alloy wire or the lead-antimony alloy coating attached to the temperature-sensitive glass ball is disconnected, thus cutting off the circuit. By controlling the shape and filling mode, the amount of liquid filled, the wall thickness of glass as well as the type of glass, the temperature of the glass ball can be set to temperature such as $57^{\circ} \mathrm{C}, 68^{\circ} \mathrm{C}, 79^{\circ} \mathrm{C}$ and $93^{\circ} \mathrm{C}$, and the operating temperature can be distinguished by the color of the internal colored liquid. The response time of action can be controlled by adjusting the diameter of the temperaturesensitive glass ball. The fuse can select the operating temperature of the temperature-sensitive blasting tube according to the actual normal operating temperature of the electrical appliance, See Fig.2.

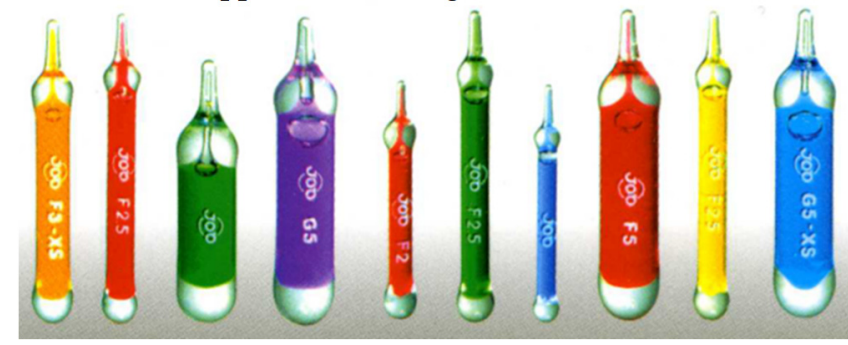

\begin{tabular}{|c|c|c|c|c|}
\hline $\begin{array}{c}\text { Operating } \\
\text { temperature, }{ }^{\circ} \mathrm{C}\end{array}$ & 57 & 68 & 79 & 93 \\
\hline Color of liquid & Orange & Red & Yellow & Green \\
\hline
\end{tabular}

Fig.2. Operating temperature of the temperature-sensitive blasting pipe

In order to realize the fire extinguishing function, we designed a U-shaped small container equipped with afire extinguishing agent filling port and a fire extinguishing agentrelease port. The release port is sealed by the temperature-sensitive blasting tube and conductsreleasing of the fire extinguishing agent. Thecontainer was filled with the fire extinguishing agent as well as certain filling pressure.

The fire extinguishing agent in the fuse is filled and pressurized (generally pressurized by $0.2 \mathrm{MPa}$ ) through the air charging port on the fire extinguishing container. The fire extinguishing agents for filling are environmentfriendly efficient gas fire extinguishing agents such as heptafluoropropane and perfluoro (2-methyl-3pentanone $)^{[7]}$, which are commonly used in the firefighting industry. These gas fire extinguishing agents can reduce temperature, extinguish fire, and have good insulation. After a fire occurs, releasing these fire extinguishing agents can extinguish fire and reduce temperature. Before a fire occurs, releasing them can realize inert and temperature reduction, thus preventing the fire from 
starting.

\subsection{Operating principle}

The fuse is connected to the circuit of the electrical appliance. In normal condition, the temperature-sensitive blasting tube seals the fire extinguishing agent container under the action of the top wire and the sealing gasket, and the circuit is normally conducted.

When it is short-circuited or overloaded, the leadantimony alloy attached to the temperature-sensitive blasting tube is overheated, resulting in that the temperature of the temperature-sensitive blasting tube is too high and then broken to lose efficacy. Subsequently, the lead-antimony alloy is disconnected, thus releasing the fire extinguishing agent while disconnecting the circuit.

When a fire or local overheating inside the electrical appliance occurs, the temperature-sensitive blasting tube is broken by heating, which leads to the disconnection of lead-antimony alloy and circuit break, then simultaneously the fire extinguishing agent is released to extinguish the fire.

\subsection{Verification results of main technical parameters}

The main technical parameters of thefuse include action response time to reach preset temperature, filling pressure and time of fire extinguishing.

The response time of the fuse is mainly controlled by controlling thethe diameter of the temperature-sensitive blasting tube. We mainly designed two types of temperature-sensitive blasting tubes with diameters of $3 \mathrm{~mm}$ and $5 \mathrm{~mm}$ respectively. We adopted the dynamic thermal test method in GB5135.1-2019 Automatic sprinkler system - part I: Sprinklers ${ }^{[8]}$ and GB5135.9-2018, Automatic sprinkler system - Part 9: Early suppression fast response (ESFR) sprinkler ${ }^{[9]}$ to verify the fuse action response time of the temperature-sensitive blasting tubes with diameters of $3 \mathrm{~mm}$ and $5 \mathrm{~mm}$ under theset operating temperature of $68^{\circ} \mathrm{C}$. The adopted experimental device was a wind tunnel experimental device, and the experimental data were shown in Table 1.

Table 1 Fuse action response time

\begin{tabular}{|c|c|c|c|}
\hline \multicolumn{2}{|c|}{$\begin{array}{c}\text { Specification of } \\
\text { temperature-sensitive } \\
\text { blasting tube }\end{array}$} & $3 \mathrm{~mm}$ & $5 \mathrm{~mm}$ \\
\hline Air temperature range, ${ }^{\circ} \mathrm{C}$ & 129 to 141 & 129 to 141 \\
\hline \multirow{2}{*}{ Air velocity range, $\mathrm{m} / \mathrm{s}$} & 2.40 to 2.60 & 1.65 to 1.85 \\
\hline \multirow{2}{*}{$\begin{array}{c}\text { Fuse } \\
\text { action } \\
\text { response } \\
\text { time, } \mathrm{s}\end{array}$} & Sample 1 & 9.0 & 17.0 \\
\cline { 2 - 4 } & Sample 2 & 8.8 & 17.8 \\
\cline { 2 - 4 } & Sample 3 & 9.1 & 18.1 \\
\cline { 2 - 4 }
\end{tabular}

\begin{tabular}{|c|c|c|c|}
\hline Sample 4 & 9.2 & 18.5 \\
\cline { 2 - 4 } & Sample 5 & 8.9 & 18.2 \\
\hline
\end{tabular}

The fire extinguishing time of the small container of the fuse is related to the type and filling pressure of the fire extinguishing agent. We set a wire fire of $100 \mathrm{~cm}^{2}$ on a circuit board of $400 \mathrm{~cm}^{2}$ as a fire model, and the small container is filled with $20 \mathrm{~g}$ heptafluoropropaneand $30 \mathrm{~g}$ perfluoro (2-methyl-3-pentanone) respectively. Fire extinguishing testswere carried out at different filling pressure. The test data are shown in Table 2.

The experimental results show that the fuse action response time of the fuse with the temperature-sensitive blasting tube in $3 \mathrm{~mm}$ diameter is within $9.2 \mathrm{~s}$, and the response time of the fuse with the temperature-sensitive blasting tube in $5 \mathrm{~mm}$ diameter is within $18.5 \mathrm{~s}$. The fire extinguishing time ofthe fuse usingheptafluoropropane as the fire extinguishing agent is less than $2 \mathrm{~s}$, and the extinguishing time of the fuse usingperfluoro(2-methyl-3pentanone) as the fire extinguishing agent is less than $1.2 \mathrm{~s}$, thus basically achieving our design goalof quick fusing and instant fire extinguishing.

Table 2 Filling pressure and fire extinguishing time of different extinguishing agents

\begin{tabular}{|c|c|c|}
\hline $\begin{array}{c}\text { Fire extinguishing } \\
\text { agent types }\end{array}$ & $\begin{array}{c}\text { Filling } \\
\text { pressure, } \mathrm{MPa}\end{array}$ & $\begin{array}{c}\text { Fire } \\
\text { extinguishing } \\
\text { time, } \mathrm{s}\end{array}$ \\
\hline Heptafluoropropane & 0.10 & 2.0 \\
\cline { 2 - 3 } & 0.15 & 1.5 \\
\cline { 2 - 3 } & 0.20 & 1.0 \\
\hline \multirow{3}{*}{$\begin{array}{c}\text { Perfluoro(2-methyl-3- } \\
\text { pentanone) }\end{array}$} & 0.10 & 1.2 \\
\cline { 2 - 3 } & 0.15 & 1.0 \\
\cline { 2 - 3 } & 0.20 & 0.8 \\
\hline
\end{tabular}

\subsection{Start-up modes of the fuse}

\subsubsection{When short circuit or overload occurs}

When a short circuit or overload occurs in the circuit, the lead-antimony alloy is overheated, causing the temperature of the temperature-sensitive glass ball to increase; when the set operating temperature (such as $68^{\circ} \mathrm{C}$ ) is reached, the temperature-sensitive glass ball is broken, the lead-antimony alloy is disconnected, and the circuit is broken. When the circuit breaks, the seal of the fire extinguishing agent container is broken, and the fire extinguishing agent is released. After the fire extinguishing agent is released, the temperature inside the appliance or the circuit board is cooled, and meanwhile an inerting space is formed, which makes the space unable to 
catch fire.

\subsubsection{When the interior of the appliance is overheated}

When the temperature inside the appliance or the circuit board is so high that reach to the set temperature (such as $68^{\circ} \mathrm{C}$ ), the temperature-sensitive glass ball is broken, the lead-antimony alloy is disconnected, and the circuit is disconnected. At the same time, the seal of the fire extinguishing agent container is broken, and the fire extinguishing agent is released; after the fire extinguishing agent is released, the temperature is reduced inside the appliance or on the circuit board, and meanwhile an inerting space is formed, which makes the space unable to catch fire.

\subsubsection{In the case of an initial fire}

When an initial fire occurs inside the appliance or the circuit board, the temperature-sensitive glass ball is heated and shattered, the lead-antimony alloy is disconnected, and the circuit is disconnected. At the same time, the seal of the fire extinguishing agent container is broken, and the fire extinguishing agent is released. After the fire extinguishing agent is released, the temperature is reduced inside the appliance or on the circuit board, and meanwhile the fire is quickly extinguished.

\section{Usage of the fuse}

Our fuse can be placed in electrical boxes and can be used in the following ways:

Select the temperature-sensitive blasting tube with suitable operating temperature according to the environment temperature of the electrical appliance;

Press the temperature-sensitive glass ball on the sealing gasket through the top wire to realize the sealing of the fire extinguishing agent container;

Fill the gas extinguishing agent (heptafluoropropane, perfluoro(2-methyl-3-pentanone) and other extinguishing agents) through the gas filling port and pressurize it with nitrogen;

Install this insurance component in the electrical appliance or on the circuit board, and connect it in series to the power circuit.

\section{Comparison with the special fire extinguishing devices used to protect electrical appliances or circuit boards at present}

At present, the special fire extinguishing devices used to protect electrical appliances or circuit boards can conduct detection and fire extinguishing only after the fire occurs, and cannot cut off the power supply synchronously. The fire detection response time of the fire extinguishing device shall exceed 30s, while the fire extinguishing time is generally about $5 \mathrm{~s}$ to $10 \mathrm{~s}$. Our fuse, firstly, can release the fire extinguishing agent and cut off the circuit before the fire caused by short circuit or overloading, to realize inert and temperature reduction of the electrical appliance or the circuit board as well as avoid fire starting. The detection response time of the temperature-sensitive blasting tube shall be within 20 s, thereby truly achieving the purposes of early detection and early fire prevention and control; and secondly, it can also release the fire extinguishing agent after the fire and the fire extinguishing time does not exceed 5s, so as to quickly achieve fire extinguish and temperature reduction, and cut off the circuit at the same time to reduce secondary damage. Therefore, it can solve the problem of releasing the fire extinguishing agent early and cut off the circuit synchronously to avoid the fire for the electrical appliances or circuit boards before the fire occurs, which can minimize the loss and avoid the occurrence of largescale fire.

\section{Application prospects}

The new environment-friendly temperature-fixing circuit fuse with the fire extinguishing function is small in size so as to be installed inside the electrical appliance, and is applicable to different sizes of appliances for fire protection. Compared with small aerosol fire extinguishing devices and fire-detecting tube fire extinguishing devices currently used to protect electrical appliances, the cost of the fuse is reduced by more than $70 \%$.In addition, we designed the temperature-sensitive blasting tubes with two diameters, and used various fuse combination schemes involving different types of fire extinguishing agents and different operating temperatures, thus providing users with a variety of choices in combination with specific scenarios. In addition, the fuse adopts environment-friendly and efficient gas fire extinguishing agents, so it is worth popularizing and applying in reduction of fire protection cost of electrical equipment as well as environmental protection.

\section{References}

1. Lu Yuxiang. Research on Electrical Fire Monitoring System [D]. Shenyang University of Technology,2016.

2. Bin Yu, Hongkun Lv, Xiaolong Zhang. Discussion on fire characteristics of electrical equipment and fire extinguishing system [J]. Electric Power Safety Technology,2020,22(08):33-37.

3. Liao Sufeng. Status and Selection of Electrical Fire Extinguishing System Technology [J]. Electronic World,2019(22):107.

4. Liu Lianxi, Zhuang Shuang et al., XF 499.1-2010, Aerosol fire extinguishing system - Part 1: Condensed aerosol fire extinguishing device, 1-4.

5. Dong Haibin, Liu Lianxi, et al., XF1167-2014, Extinguishing equipment with fire detection tube, 14.

6. Zhang Shaoyu, Chuai Fengying, etc., GB18428-2010, Glass bulbs used for automatic fire extinguishing 
systems, 1-6.

7. Zhuang Shuang, Li Shu et al., GB 18614-2012, Fire extinguishing agents - heptafluoropropane (HFC227ea), 1-8.

8. Zhang Shaoyu, Chuai Fengying, et al., GB5135.12019, Automatic sprinkler system - Part 1: Sprinkler, 32-34.

9. Yang zhenming, Liu Xin et al., GB5135.9-2018, Automatic sprinkler system - Part 9: Early suppression fast response (ESFR) sprinkler, 22-24. 